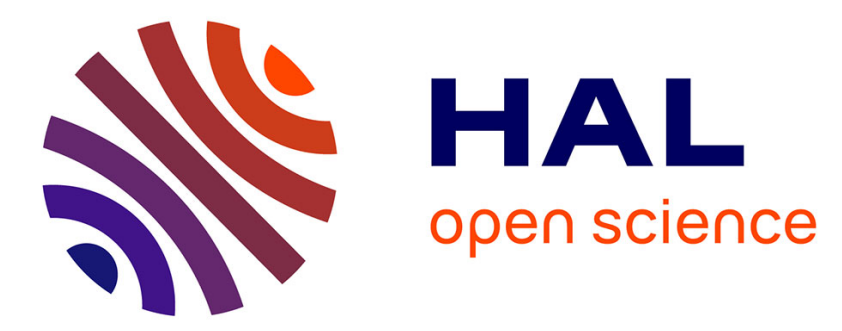

\title{
Nonlinear Control Design for a Multi-Terminal VSC-HVDC System
}

Yijing Chen, Jing Dai, Gilney Damm, Françoise Lamnabhi-Lagarrigue

\section{To cite this version:}

Yijing Chen, Jing Dai, Gilney Damm, Françoise Lamnabhi-Lagarrigue. Nonlinear Control Design for a Multi-Terminal VSC-HVDC System. 2013 European Control Conference (ECC), Jul 2013, Zurich, Switzerland. pp.3536 - 3541, 10.23919/ECC.2013.6669665 . hal-00826025

\section{HAL Id: hal-00826025 \\ https://hal-centralesupelec.archives-ouvertes.fr/hal-00826025}

Submitted on 30 Mar 2021

HAL is a multi-disciplinary open access archive for the deposit and dissemination of scientific research documents, whether they are published or not. The documents may come from teaching and research institutions in France or abroad, or from public or private research centers.
L'archive ouverte pluridisciplinaire HAL, est destinée au dépôt et à la diffusion de documents scientifiques de niveau recherche, publiés ou non, émanant des établissements d'enseignement et de recherche français ou étrangers, des laboratoires publics ou privés. 


\title{
Nonlinear Control Design and Analysis of a Multi-Terminal VSC-HVDC System
}

\author{
Yijing Chen ${ }^{1}$, Jing Dai ${ }^{1}$, Gilney Damm ${ }^{2}$, Françoise Lamnabhi-Lagarrigue ${ }^{1}$
}

\begin{abstract}
This paper presents a nonlinear control strategy based on dynamic feedback linearization control theory and a backstepping-like procedure for a multi-terminal voltagesource converter based high-voltage direct current (multiterminal VSC-HVDC) system. The controller is able to provide global asymptotic stability for the power transmission system consisting of $N$ terminals. Furthermore it is shown that the remaining zero dynamics (mostly representing the DC network) are also exponentially stable, and then the whole system can be shown asymptotically stable. These results are obtained by a rigorous stability proof for the whole system under the proposed controller, and its performance is illustrated by computer simulations.
\end{abstract}

\section{INTRODUCTION}

With the development of wind, solar and other renewable energy sources, there is an urgent need to integrate these decentralized and relatively small-scale power plants into the grid in an economical and environmentally friendly way. Furthermore, the increase of electricity demand requires the expansion of grid capacity. But it is very hard to increase the grid through overhead AC lines, which occupy large transmission line corridors. For both cases, Voltage-Source Converter based High-Voltage Direct Current (VSC-HVDC) multipoint networks could be a good solution.

At present, over $90 \mathrm{DC}$ transmission projects exist in the world, the vast majority for point-to-point two-terminal HVDC transmission system and only two for multi-terminal HVDC (MTDC) system. The traditional two-terminal HVDC transmission system can only carry out point-to-point power transfer. Under the requirements of the economic development and the construction of the power grid, it is necessary to require that the DC grid can achieve power exchanges among multiple power suppliers and multiple power consumers. Therefore, the MTDC system based on the two-terminal HVDC system draws more and more attention. MTDC transmission system is a DC transmission network connecting more than two converter stations (AC/DC,DC/DC). It offers a large transmission capacity (larger than the $\mathrm{AC}$ network) and can provide a more flexible, efficient transmission way. The main applications of MTDC system include the power exchange among multi-points, integrating isolated asynchronous networks, and integrating scattered power plants like offshore renewable energy sources such as wind, hydro, solar.

\footnotetext{
${ }^{1}$ Y. Chen, J. Dai and F. Lamnabhi-Lagarrigue are with Laboratoire des Signaux et Systèmes (LSS), Supélec, 3 rue Joliot-Curie, 91192 Gif-surYvette, France (tel: +33 1698517 77, e-mail: yijing.chen@1ss.supelec.fr, jing.dai@ supelec.fr).

${ }^{2}$ G. Damm is with Laboratoire IBISC, Université d'Evry-Val d'Essonne, 40 rue du Pelvoux, 91020 Evry, France (e-mail: gilney.damm@ibisc.fr)
}

On the other hand, MTDC system brings several stability problems. The strong interaction between DC and AC networks may lead to a significant decrease in the overall system performance and even threaten the stability and safety of the system. Therefore, it is important to perform a rigorous mathematical stability analysis for the MTDC system.

A large amount of research on two-terminal VSC HVDC control has been carried out [1], [2], [3], [4]. In [1], an equivalent continuous-time averaged state-space model is presented and a robust DC-bus voltage control scheme is proposed highlighting the existence of fast and slow dynamics that can be associated to the inner current control loop and outer DC-bus voltage control loop. Reference [3] proposes a control strategy under balanced and unbalanced network conditions, which contains two sets of controller: a main controller in the positive $d q$ frame using decoupling control, and an auxiliary controller using coupling control. However, the above mentioned controllers were designed for a standard two-terminal VSC-HVDC system, not for multi-terminal VSC-HVDC system. In [5], [6], [7], control strategies of VSC based multi-terminal were investigated. Reference [7] uses a droop control scheme to control the DC voltage. Reference [5] presents a multi-point DC voltage control and [6] proposes a scheme for controlling and coordinating the grid. However, the previously mentioned articles came from the power systems' community, and as a consequence, did not provide stability proofs.

In the present paper, a control strategy is formally designed with its mathematical stability analysis for a multiterminal HVDC system. The controller is developed following a dynamic feedback linearization strategy that, by a naturally decoupled time-scale phenomenon, represents a backstepping-like control strategy (see [8][9][10]). This controller assures global asymptotic stability for the power transmission system consisting of $N$ terminals. In a second step, the behavior of the remaining states of the system (known as the zero dynamics) is analyzed, which is given by the transmission network. And the zero dynamics are shown to be exponentially stable. It can then be seen that the whole MTDC system is asymptotically stable. This paper is organized into five sections. In Section II, a dynamic multi-terminal VSC HVDC model is given. In Section III, a feedback control law is developed. Simulations are carried out in Section IV. Conclusions are drawn in Section V. 


\section{Modeling OF A MULTi-TERMinal VSC-HVDC SYSTEM}

This section introduces the state-space model of a multiterminal VSC-HVDC system established in the synchronous $d q$ frame, which allows for a decoupled control on the active and the reactive power, where the high-frequency PWM characteristics of the power electronics are neglected. Only the balanced condition is considered in this paper, i.e. the three phases have identical parameters and their voltages and currents have the same amplitude while phase-shifted $120^{\circ}$ between themselves.

A converter of a multi-terminal VSC HVDC system connected to other converters is shown in Fig. 1.

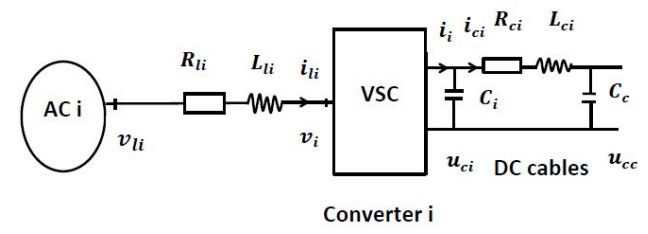

Fig. 1. One terminal in a multi-terminal VSC Transmission System

\section{AC network}

On the AC side of the converter station, the Kirchhoff voltage law leads to the system expressed in $d q$ synchronous reference frame rotating at the pulsation $\omega_{i}$ :

$$
\begin{aligned}
& v_{l i d}-R_{l i} i_{l i d}-L_{l i} \frac{d i_{l i d}}{d t}+\omega_{i} L_{l i} i_{l i q}-v_{i d}=0 \\
& v_{l i q}-R_{l i} i_{l i q}-L_{l i} \frac{d i_{l i q}}{d t}-\omega_{i} L_{l i} i_{l i d}-v_{i q}=0
\end{aligned}
$$

By using Pulse Width Modulation (PWM) technology, the amplitude of the converter output voltage $v_{i d}$ and $v_{i q}$ are controlled by the modulation index as:

$$
\begin{aligned}
v_{i d} & =\frac{v_{i d w}}{2} u_{c i} \\
v_{i q} & =\frac{v_{i q w}}{2} u_{c i}
\end{aligned}
$$

By neglecting the resistance of the converter reactor and switching losses, the instantaneous active power and reactive power on the $\mathrm{AC}$ side of the converters can be expressed as follows:

$$
\begin{aligned}
P_{l i} & =\frac{3}{2}\left(v_{l i d} i_{l i d}+v_{l i q} i_{l i q}\right) \\
Q_{l i} & =\frac{3}{2}\left(v_{l i q} i_{l i d}-v_{l i d} i_{l i q}\right)
\end{aligned}
$$

DC line

By applying the Kirchhoff voltage and current laws to the DC circuit, the DC side of the rectifier is modelled by the following differential equations:

$$
\begin{aligned}
\frac{d u_{c i}}{d t} & =-\frac{1}{C_{i}} i_{c i}+\frac{1}{C_{i}} i_{i} \\
\frac{d i_{c i}}{d t} & =\frac{1}{L_{c i}} u_{c i}-\frac{R_{c i}}{L_{c i}} i_{c i}-\frac{1}{L_{c i}} u_{c c}
\end{aligned}
$$

\section{$A C-D C$ power coupling}

Considering the active power balance on both sides of the converter, we have $u_{c i} i_{i}=v_{i A} i_{l i A}+v_{i B} i_{l i B}+v_{i C} i_{l i C}$. Thus, $i_{i}$ can be expressed as the following equations:

$$
i_{i}=\frac{3}{4}\left(v_{i d w} i_{l i d}+v_{i q w} i_{l i q}\right)
$$

The interconnection among $N$ terminals, as shown in Fig. 2, is represented as follows:

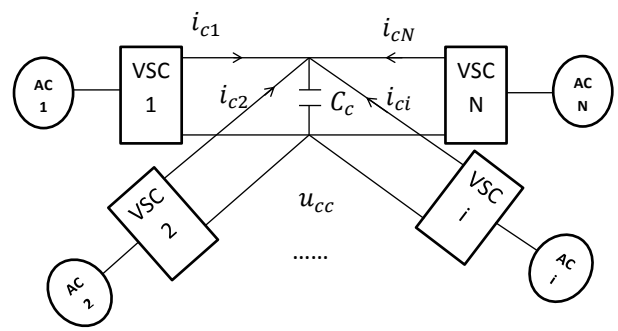

Fig. 2. The interconnection of a multi-terminal VSC Transmission System

$$
\frac{d u_{c c}}{d t}=\frac{1}{C_{c}} \sum_{i=1}^{N} i_{c i}
$$

\section{Global model}

The full state-space model of $N$-terminal VSC-HVDC system is written as follows:

$$
\left\{\begin{array}{l}
\dot{i}_{l i d}=-\frac{R_{l i}}{L_{l i}} i_{l i d}+\omega_{i} i_{l i q}-\frac{1}{L_{l i}} v_{i d w} \frac{u_{c i}}{2}+\frac{1}{L_{l i}} v_{l i d} \\
\dot{i}_{l i q}=-\frac{R_{l i}}{L_{l i}} i_{l i q}-\omega_{i} i_{l i d}-\frac{1}{L_{l i}} v_{i q w} \frac{u_{c i}}{2}+\frac{1}{L_{l i}} v_{l i q} \\
\dot{u}_{c i}=-\frac{1}{C_{i}} i_{c i}+\frac{1}{C_{i}} \frac{3}{4}\left(v_{i d w} i_{l i d}+v_{i q w} i_{l i q}\right) \\
\dot{i}_{c i}=\frac{1}{L_{c i}} u_{c i}-\frac{R_{c i}}{L_{c i}} i_{c i}-\frac{1}{L_{c i}} u_{c c} \\
\dot{u}_{c c}=\frac{1}{C_{c}}\left(\sum_{i=1}^{N} i_{c i}\right)
\end{array}\right.
$$

where $i=1, \cdots, N$.

The global state-space model of the multi-terminal VSCHVDC system is summarized as follows:

- State variables: $i_{l i d}, i_{l i q}, u_{c i}, i_{c i}, u_{c c}$.

- Control variables: $v_{i d w}, v_{i q w}$.

- External parameters: $v_{l i d}, v_{l i q}$.

- External references provided by a higher level controller named the HVDC secondary controller: $u_{c i}^{*}, Q_{l i}^{*}$.

- The dimension of the system (9) is $4 N+1$.

\section{CONTROL SCHEME}

In this part we will present the detailed synthesis of the controller for one of the terminals, i.e. addressing the converter's DC voltage $u_{c i}$ and reactive power $Q_{l i}$.

For the converter modelled by the first three equations of the system (9), it is desired that the $d q$ currents $i_{l i d}, i_{l i q}$ and the DC voltage $u_{c i}$ track their reference values. 
The control structure is mainly based on the following physical considerations:

- The dynamics of the original system expressed by (9) highlights a separation into fast and slow dynamics, where the DC voltage equation represents the slow dynamics, and the $d q$ current equations represent the fast dynamics. Thus, this multitime-scale behaviour suggests to apply a cascaded control system. The inner control loop will control the fast dynamics $i_{l i d}$ and $i_{l i q}$ and the outer control loop will regulate the slow dynamics $u_{c i}$ and control reactive power $Q_{i}$. The outputs of the outer control loop provides the current reference points in the $d q$ frame $i_{l i d}^{*}$ and $i_{l i q}^{*}$ for the inner loop system.

- We consider $d q$ frame right orientation such that $v_{l i q}=$ 0 , then (4) can be written as, $Q_{l i}=-\frac{3}{2} v_{l i d} i_{l i q}$, which means that the reactive power is directly controlled $i_{l 1 q}$.

A backstepping-like procedure is carried out for designing the control scheme. In the first step, the backstepping-like procedure requires the fast dynamics $\mathrm{AC}$ currents $i_{l i d}$ and $i_{l i q}$ to follow their reference trajectories (yet to be designed), which means to eliminate the $d q$ current errors $\widetilde{i}_{l i d}$ and $\widetilde{i}_{l i q}$ where $\widetilde{i}_{l i d}=i_{l i d}-i_{l i d}^{*}, \widetilde{i}_{l i q}=i_{l i q}-i_{l i q}^{*}$.

Following a feedback linearization objective, we design the control laws:

$$
\begin{aligned}
& u_{i d}=\dot{i}_{l i d} \triangleq \dot{\widetilde{i}}_{l i d}+\dot{i}_{l i d}^{*} \\
& u_{i q}=\dot{i}_{l i q} \triangleq \dot{\widetilde{i}}_{l i q}+\dot{i}_{l i q}^{*}
\end{aligned}
$$

The currents $i_{l i d}$ and $i_{l i q}$ are controlled independently by the auxiliary inputs $u_{i d}$ and $u_{i q}$ obtaining the new systems as follows:

$$
\begin{aligned}
& v_{i d w}=\frac{2 L_{l i}}{u_{c i}}\left(-\frac{R_{l i}}{L_{l i}} i_{l i d}+\omega_{i} i_{l i q}+\frac{1}{L_{l i}} v_{l i d}-u_{i d}\right) \\
& v_{i q w}=\frac{2 L_{l i}}{u_{c i}}\left(-\frac{R_{l i}}{L_{l i}} i_{l i q}-\omega_{i} i_{l i d}+\frac{1}{L_{l i}} v_{l i q}-u_{i q}\right)
\end{aligned}
$$

To assure that the errors $\widetilde{i}_{l i d}$ and $\widetilde{i}_{l i q}$ will converge to zero, as well as good steady states, it is proposed the following augmented state:

$$
\begin{aligned}
& \dot{\varphi}_{i d}=\widetilde{i}_{l i d} \\
& \dot{\vec{i}}_{l i d}=-k_{i d} \widetilde{i}_{l i d}-\lambda_{i d} \varphi_{i d}
\end{aligned}
$$

and

$$
\begin{aligned}
& \dot{\varphi}_{i q}=\widetilde{i}_{l i q} \\
& \dot{\widetilde{i}}_{l i q}=-k_{i q} \widetilde{i}_{l i q}-\lambda_{i q} \varphi_{i q}
\end{aligned}
$$

where $k_{i d}, k_{i q}, \lambda_{i d}$ and $\lambda_{i q}$ are positive constants. Thus, we have:

$$
\begin{aligned}
& u_{i d}=-k_{i d} \widetilde{i}_{l i d}-\lambda_{i d} \varphi_{i d}+\dot{i}_{l i d}^{*} \\
& u_{i q}=-k_{i q} \widetilde{i}_{l i q}-\lambda_{i q} \varphi_{i q}+\dot{i}_{l i q}^{*}
\end{aligned}
$$

The second step of the backstepping-like procedure determines the behaviour of the converter, which include DC voltage control and reactive power control. The outputs of this step provide the $d q$ current reference values for $d q$ currents.

The trajectory $i_{l i q}^{*}$ is obtained directly from the reactive power's reference provided by the secondary level (possibly from the AC voltage controller):

$$
i_{l i q}^{*}=-\frac{2}{3} \frac{Q_{l i}^{*}}{v_{l i d}}
$$

One of the goals of the proposed controller is to keep the DC voltage constant at its reference point $u_{c i}^{*}$. It is this DC voltage controller that provides $i_{\text {lid }}^{*}$ to the inner controllers.

Placing (11) into the third euqation of (9), we have:

$$
\begin{aligned}
\dot{u}_{c i}=-\frac{1}{C_{i}} i_{c i}+\frac{3}{2} \frac{1}{C_{i} u_{c i}} & {\left[i_{l i d}\left(-R_{l i} i_{l i d}+v_{l i d}-L_{l i} u_{i d}\right)\right.} \\
& \left.+i_{l i q}\left(-R_{l i} i_{l i q}+v_{l i q}-L_{l i} u_{i q}\right)\right]
\end{aligned}
$$

Then, by substituting (11) into (16), the DC voltage dynamics is given by:

$$
\begin{aligned}
\dot{u}_{c i}= & -\frac{1}{C_{i}} i_{c i}+\frac{3}{2} \frac{1}{C_{i} u_{c i}} . \\
& {\left[i_{l i d}\left(-R_{l i} i_{l i d}+v_{l i d}+L_{l i} k_{i d} \widetilde{i}_{l i d}+L_{l i} \lambda_{i d} \varphi_{i d}-L_{l i} \dot{i}_{l i d}^{*}\right)\right.} \\
+ & i_{l i q}\left(-R_{l i} i_{l i q}+v_{l i q}+L_{l i} k_{i q} \widetilde{i}_{l i q}+L_{l i} \lambda_{i q} \varphi_{i q}-L_{l i} \dot{i}_{l i q}^{*}\right)
\end{aligned}
$$

Since it is aimed to maintain the DC voltage $u_{c i}$ at its set value, the desired dynamics of voltage error $\widetilde{u}_{c i}$ is expressed as:

$$
\begin{aligned}
& \dot{\varphi}_{c i}=\widetilde{u}_{c i} \\
& \dot{\widetilde{u}}_{c i}=-k_{c i} \tilde{u}_{c i}-\lambda_{c i} \varphi_{c i}
\end{aligned}
$$

where $\tilde{u}_{c i}=u_{c i}-u_{c i}^{*}$. The above equation can also be written as:

$$
\dot{u}_{c i}=-k_{c i} \widetilde{u}_{c i}-\lambda_{c i} \varphi_{c i}+\dot{u}_{c i}^{*}
$$

Since the desired values for $u_{c i}^{*}, Q_{l i}^{*}$ are constant, $\dot{u}_{c i}^{*}$ and $i_{l i q}^{*}$ are taken as zero.

It is then clear that to transform the actual dynamics (17) into the desired (18b), it's necessary to apply the control:

$$
\begin{aligned}
\dot{i}_{l i d}^{*}= & -\frac{2}{3} \frac{u_{c i}}{i_{l i d}} \frac{C i}{L_{l i}}\left(-k_{c i} \widetilde{u}_{c i}-\lambda_{c i} \varphi_{c i}+\frac{i_{c i}}{C_{i}}\right)+\frac{u_{c i}}{2 L_{l i}} \frac{i_{l i q}}{i_{l i d}} v_{i q w} \\
& +\left(-\frac{R_{l i}}{L_{l i}} i_{l i d}+\omega_{i} i_{l i q}+\frac{v_{l i d}}{L_{l i}}+k_{i d} \widetilde{i}_{l i d}+\lambda_{i d} \varphi_{i d}\right)
\end{aligned}
$$

The main result of this paper can be then summarized in the form of the theorem:

Theorem 1: The multi-terminal VSC-HVDC system described by (9) under the control laws (11)-(20) is globally asymptotically stabilized to the actual reference values $u_{c i}^{*}$ and $Q_{l i}^{*}$. Furthermore, this result is independent of the network's parameters $L_{c i}, R_{c i}, C_{c i}$.

Proof: In the considered case, the $N$ converters drive the DC voltage. It is desired to keep $u_{c i}$ and $Q_{l i}$ at their reference values $u_{c i}^{*}$ and $Q_{l i}^{*}$. Thus the outputs of the system can be defined as:

$$
y=\left[\begin{array}{ll}
u_{c i} & Q_{l i}
\end{array}\right]^{T}
$$


From the previous section, we know that $i_{l i d}^{*}, i_{l i q}^{*}$ are defined by (15) and (20).

To simplify our problem, at first, we shift the reference values of the whole system to the origins and the following new state variables are introduced:

$$
\tilde{x}=\left[\begin{array}{lllll}
\widetilde{i}_{l i d} & \widetilde{i}_{l i q} & \widetilde{u}_{c i} & \widetilde{i}_{c i} & \widetilde{u}_{c c}
\end{array}\right]^{T}
$$

where $\widetilde{i}_{c i}=i_{c i}-i_{c i}^{*}, \widetilde{u}_{c c}=u_{c c}-u_{c c}^{*}$ with $i_{c i}^{*}$ and $u_{c c}^{*}$ the equilibrium values of $i_{c i}$ and $u_{c c}$.

And the new output error variables as follows:

$$
\widetilde{y}=\left[\widetilde{u}_{c i} \widetilde{Q}_{l i}\right]^{T}
$$

where $\widetilde{Q}_{l i}=Q_{l i}-Q_{l i}^{*}$.

The system (9) can be expressed in the new error variables as:

$$
\begin{aligned}
& \int_{\frac{\widetilde{d i}_{l i d}}{d t}}=-\frac{R_{l i} \widetilde{i}_{l i d}+\omega_{i} \widetilde{i}_{l i q}-\frac{1}{L_{l i}} v_{i d w} \frac{\widetilde{u}_{c i}}{2}}{\widetilde{R}_{l i \sim} \sim} \\
& \frac{\widetilde{d i}_{l i q}}{d t}=-\frac{R_{l i}}{L_{l i}} \widetilde{i}_{l i q}-\omega_{i} \widetilde{i}_{l i d}-\frac{1}{L_{l i}} v_{i q w} \frac{\widetilde{u}_{c i}}{2} \\
& \left\{\frac{d \widetilde{u}_{c i}}{d t}=-\frac{1}{C_{i}} \widetilde{i}_{c i}+\frac{1}{C_{i}} \frac{3}{4}\left(v_{i d w} \widetilde{i}_{l i d}+v_{i q w} \widetilde{i}_{l i q}\right)\right. \\
& \frac{\widetilde{d i}_{c i}}{d t}=\frac{1}{L_{c i}} \widetilde{u}_{c i}-\frac{R_{c i}}{L_{c i}} \widetilde{i}_{c i}-\frac{1}{L_{c i}} \widetilde{u}_{c c} \\
& \frac{d \widetilde{u}_{c c}}{d t}=\frac{1}{C_{c}}\left(\sum_{i=1}^{N} \widetilde{i}_{c i}\right)
\end{aligned}
$$

where $i=1, \cdots, N$.

Now in order to analyze the stability of the new system (24), we first divide the state varibles $\tilde{x}$ into two parts:

$$
\begin{aligned}
\eta & =\left[\begin{array}{ll}
\tilde{i}_{c i} & \tilde{u}_{c c}
\end{array}\right]^{T}, \\
\xi & =\left[\begin{array}{lll}
\tilde{i}_{l i d} & \tilde{i}_{l i q} & \tilde{u}_{c i}
\end{array}\right]^{T} .
\end{aligned}
$$

The system (24) can be considered as in the normal form:

$$
\begin{aligned}
& \dot{\eta}=f_{1}(\eta, \xi), \\
& \dot{\xi}=f_{2}(\eta, \xi, u) .
\end{aligned}
$$

with

$$
u=f_{3}(\eta, \xi)
$$

This is the standard nonlinear zero dynamics form [9]. If a system is in the normal form (26), when $\xi$ is identically zero, the behaviour of the system (26) is governed by the differential equation:

$$
\dot{\eta}=f_{1}(\eta, 0)
$$

The dynamics of (28) correspond to the "internal" behaviour of the system, which are called the zero dynamics of the system. Suppose that $\eta=0$ of the zero dynamics of the system (26) is globally asymptotically stable and $\xi$ is also globally asymptotically stable under the feedback control law (27), then the whole system (26) is stabilized by the feedback control law $(27)$ at $(\eta, \xi)=(0,0)[9]$.

The next step is to study the behaviours of $\eta, \xi$ respectively. Applying the controller (11) and (12) (13) (18), the closed-loop error system can be written as:

$$
\dot{\zeta}=A \zeta
$$

where $\zeta=\left[\begin{array}{llllll}\varphi_{i d} & \widetilde{i}_{l i d} & \varphi_{i q} & \widetilde{i}_{l i q} & \varphi_{c i} & \widetilde{u}_{c i}\end{array}\right]^{T}$ and $A=$ $\operatorname{diag}\left(A_{i d}, A_{i q}, A_{c i}\right)$ with

$$
\begin{aligned}
A_{i d} & =\left(\begin{array}{cc}
0 & 1 \\
-\lambda_{i d} & -k_{i d}
\end{array}\right) \\
A_{i q} & =\left(\begin{array}{cc}
0 & 1 \\
-\lambda_{i q} & -k_{i q}
\end{array}\right) \\
A_{c i} & =\left(\begin{array}{cc}
0 & 1 \\
-\lambda_{c i} & -k_{c i}
\end{array}\right)
\end{aligned}
$$

It is easy to verifier that matrix $A$ is Hurwitz. Thus, $\zeta$ is globally exponentially stable with the proposed control law (11). It is now necessary to study the behaviour of the state variables $\eta$ when $\xi$ converge to zero. In fact, when $\xi=0, \eta$ is governed by the following differential equation:

$$
\left[\begin{array}{c}
\dot{\vec{i}}_{c 1} \\
\dot{\vec{i}}_{c 2} \\
\vdots \\
\dot{\vec{i}}_{c N} \\
\dot{\widetilde{u}}_{c c}
\end{array}\right]=\left[\begin{array}{ccccc}
-\frac{R_{c 1}}{L_{c 1}} & 0 & \ldots & 0 & -\frac{1}{L_{c 1}} \\
0 & -\frac{R_{c 2}}{L_{c 2}} & \ldots & 0 & -\frac{1}{L_{c 2}} \\
\vdots & \vdots & \vdots & \vdots & \vdots \\
0 & 0 & \ldots & -\frac{R_{c N}}{L_{c N}} & -\frac{1}{L_{c N}} \\
\frac{1}{C_{c}} & -\frac{1}{C_{c}} & \ldots & -\frac{1}{C_{c}} & 0
\end{array}\right]\left[\begin{array}{c}
\widetilde{i}_{c 1} \\
\widetilde{i}_{c 2} \\
\vdots \\
\widetilde{i}_{c N} \\
\widetilde{u}_{c c}
\end{array}\right]
$$

Thus, the zero dynamics of the system (24) is:

$$
f_{1}(\eta, 0)=B \eta
$$

where $B=\left[\begin{array}{ccccc}-\frac{R_{c 1}}{L_{c 1}} & 0 & \ldots & 0 & -\frac{1}{L_{c 1}} \\ 0 & -\frac{R_{c 2}}{L_{c 2}} & \ldots & 0 & -\frac{1}{L_{c 2}} \\ \vdots & \vdots & \vdots & \vdots & \vdots \\ \frac{1}{C_{c}} & -\frac{1}{C_{c}} & \ldots & -\frac{1}{C_{c}} & 0\end{array}\right]$.

The characteristic polynomial of matrix $B$ is in the following form:

$$
f(\lambda)=\lambda^{N+1}+\sum_{i=0}^{N} a_{i} \lambda^{i}
$$

where $\lambda$ are the eigenvalues of matrix $B$ and $a_{i}, i=0, \ldots, N$ are positive.

For all $\lambda, \operatorname{Re}(\lambda)$ is negative and as consequence, $B$ is Hurwitz and then the zero dynamics of the system (24) $\dot{\eta}=$ $f_{1}(\eta, 0)$ is globally exponentially stable.

From the above proof, the designed control law (11) can globally exponentially stabilize $\xi$ and the zeros dynamics (28) is also globally exponentially stable. Finally the whole system (24) is globally asymptotically stabilized at $(\eta, \xi)=$ $(0,0)$ by the proposed controller.

\section{Simulation RESUlts}

The proposed controller is tested in computer simulations presenting a three-terminal VSC-HVDC system, which is shown in Fig. 3. These three VSC terminal operate in DC voltage control mode. The parameter values are presented in Table I. We choose the pulsation $\omega_{i}=314$, the capacitor $C_{i}=12 \times 10^{-6} \mathrm{~F}$ and the RMS value of $v_{l i}=230 \times 10^{3} \mathrm{~V}$. 
TABLE I

PARAMETER VALUES OF EACH AC AREA.

\begin{tabular}{|c|c|c|c|c|}
\hline \hline & $R_{l i}$ & $L_{l i}$ & $R_{c i}$ & $L_{c i}$ \\
\hline AC 1 & 13.79 & $31.02 \mathrm{e}-3$ & 0.2085 & 0.0024 \\
\hline AC 2 & 12.79 & $33.02 \mathrm{e}-3$ & 0.2 & 0.001 \\
\hline AC 3 & 13.57 & $40.02 \mathrm{e}-3$ & 0.235 & 0.0035 \\
\hline
\end{tabular}

TABLE II

SEQUENCE OF EVENTS ASSUMED IN SIMULATION

\begin{tabular}{|c|c|}
\hline \hline Time (s) & Events \\
\hline 0 & $u_{c 1}=101 \mathrm{KV}, u_{c 2}=100 \mathrm{KV}, u_{c 3}=99.8 \mathrm{KV}$ \\
\hline 1 & Set the reference values: \\
& $u_{c 1}=101.2 \mathrm{KV}, u_{c 2}=101 \mathrm{KV}, u_{c 3}=99.9 \mathrm{KV}$ \\
\hline 4 & Set the reference value: $u_{c 1}=102.2 \mathrm{KV}$ \\
\hline 5 & Set the reference value: $u_{c 2}=102.0 \mathrm{KV}$ \\
\hline 6 & Set the reference value: $u_{c 3}=100.9 \mathrm{KV}$ \\
\hline \hline
\end{tabular}

The feedback control gains are given as $k_{i d}=100, \lambda_{i d}=$ $100, k_{i q}=100, \lambda_{i q}=100, k_{c i}=25, \lambda_{c i}=5$. The sequence of values listed in Table II is used when carrying out the simulations. And In our simulations, all reactive powers $Q_{l 1}$, $Q_{l 2}$ and $Q_{l 3}$ are set up to zero which allow unitary power factor, which means that $i_{l 2 q}^{*}, i_{l 2 q}^{*}$ and $i_{l 3 q}^{*}$ are zero.

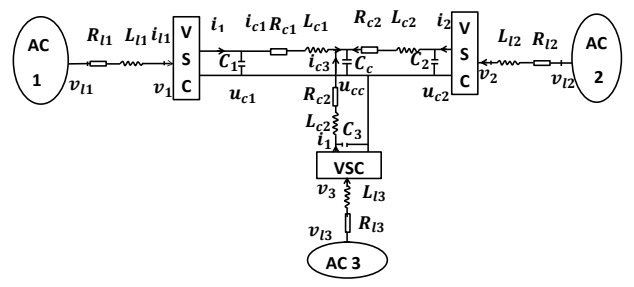

Fig. 3. A three-terminal VSC-HVDC Transmission System

Simulation results are shown in Fig. (4)-(9). The regulation behaviours of each converter's DC voltage are illustrated in Fig. (4), (5) and (6) where the black curve represents each DC voltage's reference value and the red one is its responses. At the start of the simulation, these terminals work at their initial reference values, then at $t=1 \mathrm{~s}$, there are a step change for each DC voltage reference values. Fig. (4)-(6) indicate that each DC voltage $u_{c i}$ reaches its new reference value before $t=2 \mathrm{~s}$. At $t=4 \mathrm{~s}$, we only give a step change for $u_{c 1}^{*}$, after then $u_{c 1}$ achieve its new reference value before $t=5$ as can be seen in Fig. (4). During $t=4 \mathrm{~s}$ to $t=5 s, u_{c 2}$ and $u_{c 3}$ keep unchanging and are still at their own reference values as shown in Fig. (5) and (6). At $t=5 s$ and $t=6 s$, when the reference values for $u_{c 2}$ and $u_{c 3}$ are reset, respectively, we find that, they attain their new references and have no effect to $u_{c 1}$.

The converter's quadrature current $i_{l i q}$ are always very close to zero no matter how the DC voltage reference value change. The reason is that the quadrature current is controlled by the reactive controller. If the reference value of $Q_{l i}$ is always zero, $i_{l i q}$ remains close to zero.

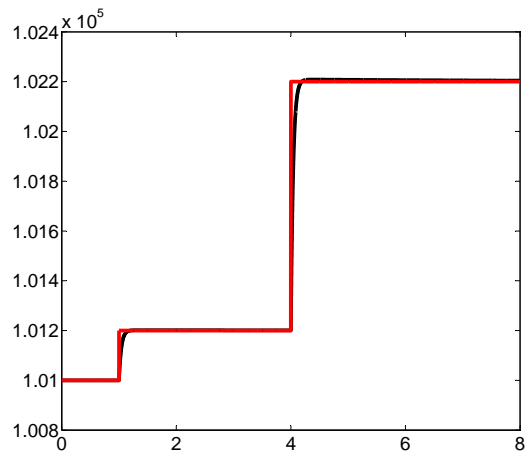

Fig. 4. DC voltage control $u_{c 1}$ reference and response

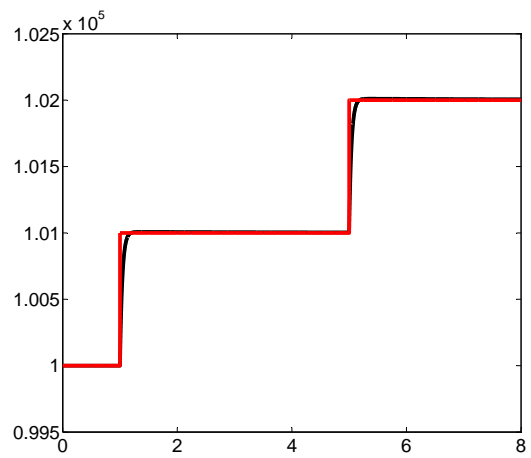

Fig. 5. DC voltage control $u_{c 2}$ reference and response

Fig. (7), (8) and (9) illustrate each converter's direct current $i_{l i d}$. We can see that, once the DC voltage reference value change, the direct current also change and reach a new reference point. It is true since $i_{l i d}^{*}$ is controlled by DC voltage controller.

\section{CONCLUSIONS}

In this paper, a nonlinear controller has been designed for the multi-terminal VSC-HVDC system. This controller is a cascade control system that exhibits a multitime-scale behaviour. The proposed control law is based on dynamic feedback linearization strategy and a backstepping-like procedure. A detailed stability analysis by means of the zero dynamics approach for the nonlinear system shows that the MTDC system is asymptotically stable. Simulation results also clearly show that the proposed control strategy contributes significantly to regulating DC-bus voltage and it highlights dynamic performances.

\section{REFERENCES}

[1] J. L. Thomas, S. Poullain, and A. Benchaib, "Analysis of a robust DC-bus voltage control system for a VSC transmission scheme," in Seventh International Conference on AC and DC Transmission (CP485), (London), 28-30 November 2001.

[2] M. Rashed, S. El-Anwar, and F. Youssef, "Nonlinear control scheme for VSC-HVDC transmission systems," in Power System Conference, 2008. MEPCON 2008. 12th International Middle-East, pp. 486 -491, march 2008. 


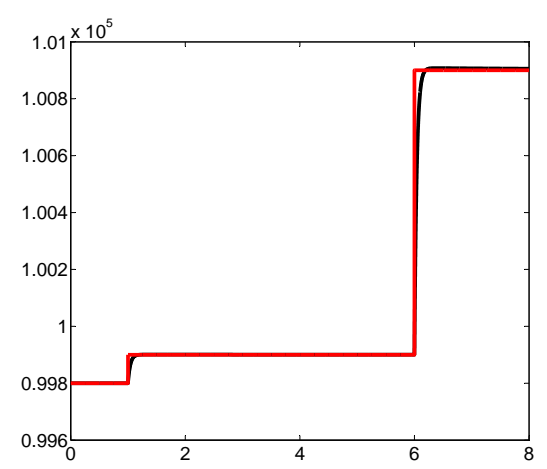

Fig. 6. DC voltage control $u_{c 3}$ reference and response

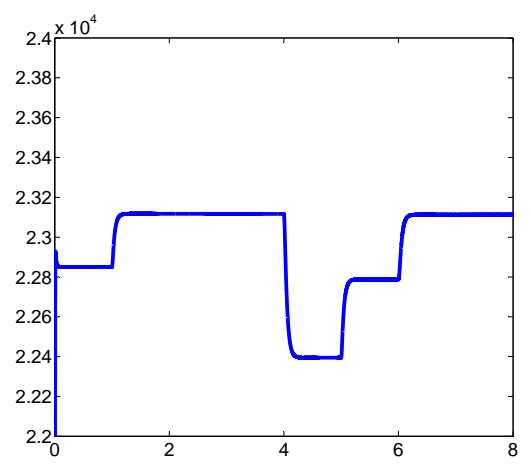

Fig. 7. DC voltage control $i_{l 1 d}$ response

[3] L. Xu and B. R. Andersen, "Control of VSC transmission systems under unbalanced network conditions," Transmission and Distribution Conference and Exposition, IEEE PES, vol. 2, pp. 626-632, 2003.

[4] L. Xu, B. Andersen, and P. Cartwright, "VSC transmission operating under unbalanced AC conditions - analysis and control design," Power Delivery, IEEE Transactions on, vol. 20, pp. 427 - 434, jan 2005.

[5] H. Chen, C. Wang, F. Zhang, and W. Pan, "Control strategy research of VSC based multiterminal HVDC system," in Power Systems Conference and Exposition, 2006. PSCE '06. 2006 IEEE PES, pp. 1986 -1990, 29 2006-nov. 12006.

[6] L. Xu, B. Williams, and L. Yao, "Multi-terminal DC transmission systems for connecting large offshore wind farms," in Power and Energy Society General Meeting - Conversion and Delivery of Electrical Energy in the 21st Century, 2008 IEEE, pp. 1-7, july 2008.

[7] O. Gomis-Bellmunt, A. Egea-Alvarez, A. Junyent-Ferre, J. Liang, J. Ekanayake, and N. Jenkins, "Multiterminal HVDC-VSC for offshore wind power integration," in Power and Energy Society General Meeting, 2011 IEEE, vol. july, pp. 1 -6, 2011.

[8] H. Khalil, Nonlinear Systems. New Jersey: Prentice Hall, 3rd ed., 1996.

[9] A. Isidori, Nonlinear Control Systems, Third Edition. Springer, 1995

[10] R. Marino and P. Tomei, Nonlinear Control Design - Geometric, Adaptive and Robust. Hemel Hempstead, London: Prentice Hall, 1995.

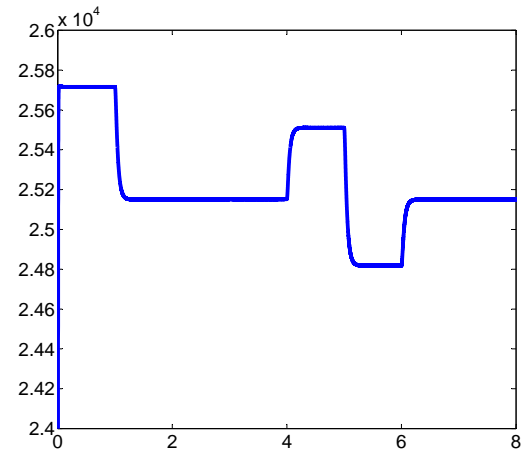

Fig. 8. DC voltage control $i_{l 2 d}$ response

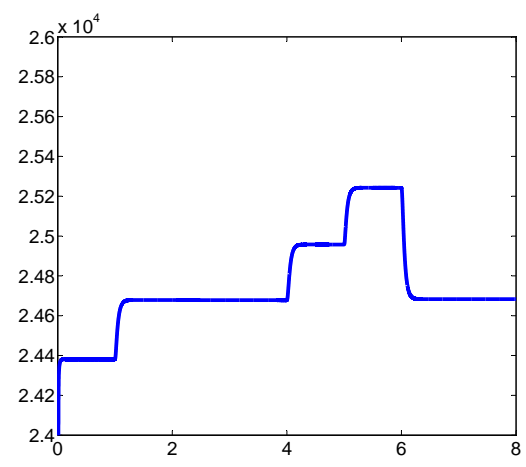

Fig. 9. DC voltage control $i_{l 3 d}$ response 